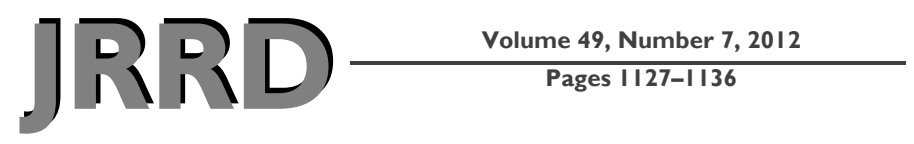

\title{
Mild traumatic brain injury and pain in Operation Iraqi Freedom/ Operation Enduring Freedom veterans
}

\begin{abstract}
Jennifer Romesser, PsyD; ${ }^{*}$ Jane Booth, PhD $;^{2}$ Jared Benge, PhD; ${ }^{3}$ Nicholas Pastorek, PhD; ${ }^{4}$ Drew Helmer, MD $^{\mathbf{5}}$
${ }^{1}$ George E. Wahlen Department of Veteran Affairs (VA) Medical Center, Mental Health, Salt Lake City, UT; and University of Utah, Department of Educational Psychology, Salt Lake City, UT; ${ }^{2}$ Michael E. DeBakey VA Medical Center, Mental Health Care Line, Houston, TX; and Baylor College of Medicine, Menninger Department of Psychiatry and Behavioral Sciences, Houston, TX; ${ }^{3}$ Jack C. Montgomery VA Medical Center, Department of Physical Medicine and Rehabilitation, Muskogee, OK; ${ }^{4}$ Michael E. DeBakey VA Medical Center, Rehabilitation Care Line, Houston, TX; and Baylor College of Medicine, Department of Physical Medicine and Rehabilitation, Houston, TX; ${ }^{5}$ Michael E. DeBakey Veteran Affairs Medical Center, PrimeCare, Neurorehabilitation: Neurons to Networks VA Rehabilitation Research and Development Traumatic Brain Injury Center of Excellence, Houston, TX; and Baylor College of Medicine, Division of General Medicine, Department of Medicine, Houston, TX
\end{abstract}

\begin{abstract}
The purpose of this study was to describe the pain experience in Operation Iraqi Freedom/Operation Enduring Freedom veterans with and without a history of mild traumatic brain injury (mTBI) who present to polytrauma clinics for evaluation and management. We sought to evaluate the relationship between a veteran's history of mTBI and posttraumatic stress (PTS) on axial pain, head/headache pain, and pain interference. We performed retrospective chart reviews of 529 Iraq/Afghanistan veterans referred for evaluation at two Department of Veterans Affairs medical centers. Problems with head/headache, low back, and neck pain were frequently endorsed. Subjective pain interference was reported in $21 \%$ of patients without a history of mTBI, 31.9\% of patients with a history of mTBI with disorientation only, and $36.1 \%$ of patients with a history of mTBI with loss of consciousness. Statistically significant differences existed between the mTBI groups on PTS symptom endorsement, and PTS was predictive of pain experience and interference. A history of mTBI with loss of consciousness predicted head/headache pain, but otherwise did not predict pain or pain interference. PTS was strongly related to the pain experience. Pain is common in polytrauma patients. PTS severity is strongly associated with both pain report and pain interference, with head/headache pain showing a unique association with a history of mTBI. Implications for evaluation and management of pain in this complex population are discussed.
\end{abstract}

Key words: back pain, headaches, loss of consciousness, mental health treatment, mild traumatic brain injury, OIF/OEF veterans, pain, pain interference, polytrauma, posttraumatic stress disorder, traumatic brain injury.

\section{INTRODUCTION}

Pain is endorsed as one of the most frequent problems in veterans of Operation Iraqi Freedom/Operation Enduring

Abbreviations: LOC $=$ loss of consciousness, $\mathrm{mTBI}=$ mild TBI, OIF/OEF = Operation Iraqi Freedom/Operation Enduring Freedom, PCL $=$ Posttraumatic Stress Disorder Checklist, PTSD = posttraumatic stress disorder, TBI = traumatic brain injury, VA = Department of Veterans Affairs.

*Address all correspondence to Jennifer Romesser, PsyD; George E. Wahlen Department of Veteran Affairs Medical Center, Mental Health, 500 Foothill Drive, 116B OPMH, Salt Lake City, UT 84148; 801-582-1565, ext 2711; fax: 801584-2544. Email: jennifer.romesser@va.gov http://dx.doi.org/10.1682/JRRD.2010.12.0238 
Freedom (OIF/OEF) [1]. Gironda et al. studied OIF/OEF servicemembers registered for medical care at a southeastern Department of Veterans Affairs (VA) hospital and found that 42 percent of 533 patients reported a current problem with pain [2]. Over 50 percent of these patients endorsed pain levels in the clinically significant range (defined as a pain rating of greater than 4 on an intensity scale of $0-10$ ). Similarly, in OIF/OEF veterans presenting for evaluation at a postdeployment health clinic, Helmer et al. found chronic widespread pain-defined in terms of the duration, distribution across the body, and perceived intensity of the pain-in 29 percent of the sample [3]. Further, the presence of chronic pain was associated with greater home and work-related disability. Back pain and headache were the most frequently reported pain symptoms in OIF/ OEF veterans [4].

While these studies highlight pain as an important postdeployment concern in the veteran population, it remains unclear what factors lead to such a high prevalence of pain in this population. One of the most obvious potential contributors to pain is a history of physical injury. Veterans are predisposed to overuse and traumatic orthopedic injuries by nature of their training and combat [5-6], and some of these injuries result in chronic musculoskeletal pain.

A second possible contributor to the relatively high prevalence of pain in returning veterans is mild traumatic brain injury (mTBI), the most common form of brain injury in veterans. Studies estimate that as many as 12 to 19 percent of OIF/OEF soldiers sustained deploymentrelated mTBI [7-8]. While most people completely recover in a matter of weeks to months following an mTBI [9-12], a small percentage of individuals report persistent postconcussive symptoms, including physical, cognitive, and emotional symptomology [13]. In addition to these commonly recognized persistent symptoms in a minority of individuals with a history of mTBI, pain is also quite commonly reported. The overall prevalence of chronic pain in the civilian TBI population is between 22 and 95 percent [14-15], with the prevalence of pain greater in the mTBI population than in those with more severe brain injuries. A meta-analysis of 10 studies with 1,046 individuals with a history of mTBI reported a pain prevalence rate of 75.3 percent $(72.7 \%-77.9 \%)$; analysis of nine studies with 1,063 severe TBI patients reported a chronic pain prevalence rate of 32.1 percent $(29.3 \%-$ $34.9 \%$ ) [16]. More than just another self-reported symp- tom, pain conditions can negatively affect recovery, vocational outcomes, and psychosocial functioning $[3,17]$.

A third contributor to the pain experience is emotional functioning. The relationship between pain and psychological distress, particularly depression and anxiety, has been well documented (e.g., Sherbourne et al. [18]). Research suggests that psychological distress may increase pain and negatively affect a person's ability to manage and cope with pain [19]. Similarly, emotional distress has been shown to increase pain experience and has a profound effect on pain report with regards to frequency, intensity, and duration.

Pain has also been identified as a risk factor for developing mental health problems. The presence of chronic pain has been found to increase risk for developing psychological disorders, specifically depression [20]. Pain interference, as measured by functional limitations secondary to pain, has been linked to depression, and there is some evidence that pain interference is a stronger predictor of depression then actual pain severity [21]. Comorbid pain and psychological factors have also been linked to poor prognostic outcome [19].

Comorbid pain and posttraumatic stress disorder (PTSD) is a commonly reported problem in veterans. Shipherd et al. documented high rates of comorbid pain (66\%) in veterans who were seen for treatment of PTSD [22]. In a sample of OIF/OEF veterans referred to a Polytrauma Network Site, 68.2 percent reported PTSD [4]. In addition to increasing the experience of pain, emotional distress such as PTSD may magnify pain and interfere with the person's ability to adapt to severe pain [23].

The frequency of physical, emotional, and neurological traumas in returning veterans makes studying pain a complex enterprise. Consider, for example, the work of Hoge et al. [7]. In this seminal study, individuals with a history of mTBI were found to have significantly worse physical health outcomes. However, veterans with a history of mTBI were also found to have much higher rates of PTSD than other military cohorts. After adjusting for emotional distress, the relationship between mTBI and physical health outcomes was no longer significant, with one notable exception: headaches were found to be more prevalent in the veterans with a history of mTBI than other servicemembers regardless of the extent of emotional distress.

While pain is a historically difficult topic to study and explore, it is clinically useful to understand the prevalence, nature, and association of pain with other conditions. To 
date, the pain experience of veterans presenting for treatment with a history of mTBI and other injuries (known within the Veterans Health Administration as polytrauma) has not been well documented. Thus, the purpose of the current study is threefold. First, we seek to describe the pain experience in OIF/OEF veterans with and without a history of mTBI. Second, we hope to elucidate the relationship between posttraumatic stress (a common comorbidity), history of brain injury, and pain in this sample. Third, we seek to evaluate the relationship between a veteran's history of injuries and current pain-related interference in daily life. Because of the high rates of headache and axial pain (i.e., neck and back) in returning veterans, we will focus our analyses on these conditions.

\section{METHODS}

\section{Participants}

This study involved a retrospective chart review of 529 OIF/OEF veterans who underwent TBI evaluations by the polytrauma teams at two different VA medical centers. Veterans were referred to the TBI Clinic following a positive screen on the Veterans Health Administration TBI Clinical Reminder [24] that was administered at an initial VA visit. A positive screen required a "yes" response to all four items (Figure).

Individuals who screened positive were administered standardized assessments of brain injury history and current symptoms as described in the "Procedure" section. Information obtained from the self-reported brain injury history was used to operationalize and stratify the sample. Individuals were categorized as having a self-reported history of mTBI as evidenced by identifying a mechanism of injury and endorsing at least one of the following: a loss of consciousness (LOC) less than $30 \mathrm{~min}$, posttraumatic amnesia for less than $24 \mathrm{~h}$, or feeling dazed for less than $24 \mathrm{~h}$ after the injury [25]. This brain injury group was further subdivided into those who reported feeling "disoriented" after their injury versus those who reported LOC, because LOC may represent a more significant neurological insult than transient feelings of being disoriented. A subset of the sample screened positive on the 4item screener and presented for evaluation, but during the full clinical interview did not report a mechanism of injury or any alteration in consciousness and thus were categorized as not having had a brain injury. We excluded 47 individuals with incomplete information about demo-
1. Did you have any injury during your deployment from any of the following? (check all that apply: fragment, bullet, explosion, etc.)

2. Did any injury you received while deployed result in any of the following? (check all that apply: being dazed, confused or "seeing stars;" not remembering the injury, losing consciousness, head injury, etc.)

3. Did any of these begin or get worse afterward? (check all that apply: dizziness, headache, memory problems, balance problems, ringing in the ears, irritability, sleep problems.)

4. In the past week, have you had any of the above problems? (check all that apply: dizziness, memory problems, etc.)

Figure.

Traumatic brain injury clinical reminder screening measure from Belanger et al. [24].

graphic characteristics, injury severity characteristics, pain or headaches, or with more than two items missing on the PTSD Checklist (PCL). Of the remaining cases, 49 who reported injury characteristics suggestive of moderate or severe TBI (e.g., LOC $>30 \mathrm{~min}$ ) were excluded. A total of 433 records were retained for the current study after inclusion and exclusion criteria were met. Additional demographic information is presented in Table 1.

\section{Procedure}

An injury self-report questionnaire was used by the polytrauma clinical services to collect demographic and military service information from each patient, injury characteristics about possible TBIs, and current symptom reports. Brain injury history questions involved asking the veteran to report the number, type, and mechanisms of injuries, as well as relevant descriptions of injury characteristics such as the distance from a blast.

Included in this questionnaire were items intended to measure the pain experience. Items included the following:

1. "In the last 30 days, have you had any problems with pain, yes or no?” If yes, the patient was asked to check all locations that apply. The options include pain in the head/headaches, legs, arms, neck, shoulders, low back, upper back, or other.

2. "In the last 30 days, how much did pain interfere with your life?” The choices included not at all, mildly, moderately, severely, and extremely. 
Table 1.

Demographic information $(N=433)$. Mean age $=31.0 \pm 8.2$ yr.

\begin{tabular}{|c|c|}
\hline Demographic & $n(\%)$ \\
\hline Sex: Male & $413(95.4)$ \\
\hline Marital Status: Married & $227(52.4)$ \\
\hline \multicolumn{2}{|l|}{ Race } \\
\hline African American & $65(15.0)$ \\
\hline Caucasian & $276(63.7)$ \\
\hline Hispanic & 75 (17.3) \\
\hline Other & 17 (3.9) \\
\hline \multicolumn{2}{|l|}{ Military Branch } \\
\hline Air Force & $16(3.7)$ \\
\hline Army & 229 (52.9) \\
\hline Marine Corps & $106(24.5)$ \\
\hline National Guard & $50(11.5)$ \\
\hline Navy & $29(6.7)$ \\
\hline \multicolumn{2}{|l|}{ Education } \\
\hline Less than HS & $1(0.2)$ \\
\hline HS diploma or equivalent & $230(53.1)$ \\
\hline Some college & $168(38.8)$ \\
\hline College graduate & 34 (7.9) \\
\hline \multicolumn{2}{|l|}{ Employment Status } \\
\hline Unemployed & $96(22.2)$ \\
\hline Student & 49 (11.3) \\
\hline Working part- or full-time & $281(64.9)$ \\
\hline Other & $7(1.6)$ \\
\hline
\end{tabular}

These items were examined to assess location of pain and pain interference (how much pain interfered with daily life).

If the veteran reported pain in the past 30 days, selfreported information about pain characteristics was used to classify the individuals according to each of the following three variables: head/headaches, axial pain (if endorsed neck, low back, or upper back pain), and pain interference, all of which were coded as binary variables: yes/no. Pain interference was operationalized as greater than moderate pain interference with life in the past 30 days (severely and extremely).

In addition to injury characteristics and pain data, veterans completed an injury severity self-report questionnaire and the PCL-Civilian Version or PCL-Military Version. The PCL operationalizes the PTSD criteria in the Diagnostic and Statistical Manual of Mental DisordersFourth Edition [26] by providing one item for each of the
17 criteria in symptom clusters B, C, and D. These forms vary only in that the phrase "stressful experience" in the civilian version is replaced by the term "stressful military experience" in eight items of the military version. Despite this slight difference in phrasing, there was no significant difference in the raw PCL scores between the two sites $(p=0.39)$, with a mean difference of only 1.43 . The forms were treated as parallel in the remaining analyses.

\section{Data Analysis}

We used PASW Statistics 18 software (IBM; Armonk, New York) for data analysis. Nonparametric tests and analyses of variance were used to compare TBI groups (no TBI, TBI with period of disorientation only, TBI with period of brief LOC) on the dependent variables including PCL score and pain variables. Logistic regression was performed to assess the effect of posttraumatic stress and TBI group in predicting membership to the three different pain conditions: axial pain, head/headache pain, and pain interference.

\section{RESULTS}

Clinical characteristics of the sample, including posttraumatic stress symptoms, pain areas, pain interference, and axial pain, are reported in Table 2.

No statistically significant differences were found between the mTBI no LOC, mTBI + LOC, and no TBI groups on the pain variables presented in Table 2. Trends were noted for differences in posttraumatic stress symptoms (PCL total score; $F=2.46, p=0.09$ ) and number of areas of pain $(F=2.85, p=0.06)$ between the groups, although further between-group contrasts are not reported because the overall difference was not statistically significant.

The next series of analyses used information on the veteran's brain injury history and PCL total score to predict the presence of head/headache pain, axial pain, or significant pain interference.

In terms of predicting significant pain interference, the full model containing all predictors was statistically significant, $\chi^{2}(3, N=433)=67.98, p<0.001$, indicating that the model was able to distinguish between respondents who did and did not report significant pain interference. The model as a whole explained between 14.5 percent (Cox and Snell $R$-squared) and 20.4 percent (Nagelkerke $R$-squared) of variance in severe pain interference status. 
Table 2.

Clinical characteristics $(N=433)$. Data shown as $n(\%)$ unless otherwise indicated.

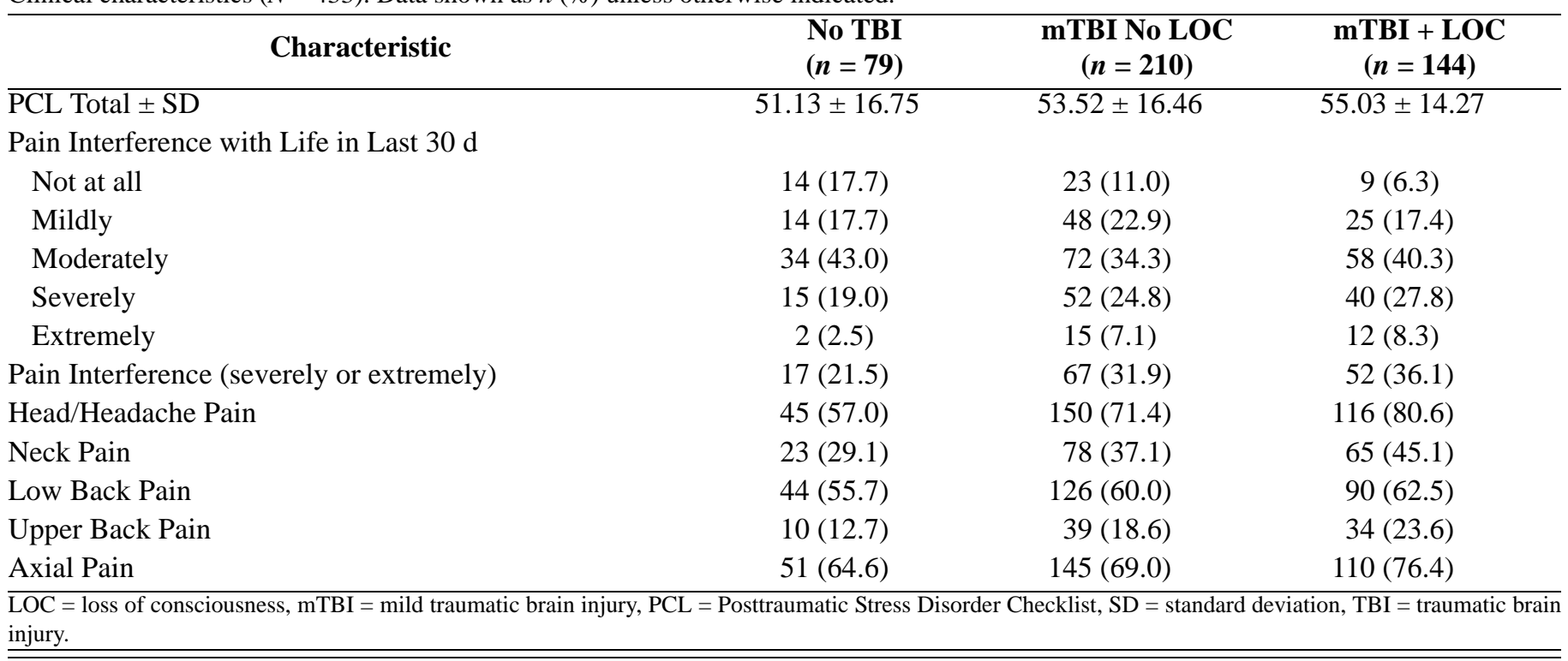

Table 3 indicates that the only statistically significant predictor of pain interference was posttraumatic stress. Note that the relatively small odds ratio refers to the odds of a single point increase on this 85-point scale affecting the criterion variable. Thus, to put the odds ratio in more meaningful units, an individual's odds of having significant pain interference increases 1.8 times for each 10 point increase on the PCL (i.e., moving from a 40 to a 50).

A similar pattern emerged when predicting axial pain, with the full model containing all predictors statistically significant, $\chi^{2}(3, N=433)=13.97, p<0.003$, indicating that the model was able to distinguish between respondents who did and did not report axial pain. The model as a whole explained between 3.2 percent (Cox and Snell $R$-squared) and 4.5 percent (Nagelkerke $R$ squared) of variance in axial pain status. Table 4 indicates that, as with pain interference, the only statistically significant predictor of axial pain was posttraumatic stress, with an odds ratio of 1.02. Again, this finding indicates that with, for example, a 10-point increase on the PCL, the risk for axial pain increases 1.2 times. An mTBI was not a significant predictor of axial pain.

In terms of head/headache pain, the full model containing all predictors was statistically significant, $\chi^{2}$ (3, $N=433)=21.05, p<0.001$, indicating that the model was able to distinguish between respondents who did and did not report head pain. Table 5 indicates that TBI was a significant predictor of head/headache pain, with a history of TBI with LOC (odds ratio $=2.90$ ) being much more strongly predictive of head/headache pain relative to the no TBI group than a history of TBI with disorientation only (odds ratio $=1.80$ ) relative to the no TBI group. PCL score was also predictive of head/headache pain, with each 10-point increase in head/headache pain increasing the odds of head/headache pain 1.2 times.

Table 3.

Logistic regression predicting likelihood of reporting pain interference.

\begin{tabular}{|c|c|c|c|c|c|c|c|}
\hline \multirow{2}{*}{ Variable } & \multirow{2}{*}{$B \pm \mathrm{SE}$} & \multirow{2}{*}{ Wald } & \multirow{2}{*}{$d f$} & \multirow{2}{*}{$p$-Value } & \multirow{2}{*}{ Odds Ratio } & \multicolumn{2}{|c|}{ 95\% CI for Odds Ratio } \\
\hline & & & & & & Lower & Upper \\
\hline Posttraumatic Stress & $0.06 \pm 0.01$ & 51.14 & 1 & $<0.001$ & 1.06 & 1.04 & 1.08 \\
\hline Disorientation Only vs No TBI & $0.43 \pm 0.34$ & 1.67 & 1 & 0.19 & 1.54 & 0.80 & 2.97 \\
\hline LOC vs No TBI & $0.59 \pm 0.35$ & 2.90 & 1 & 0.09 & 1.81 & 1.04 & 1.08 \\
\hline
\end{tabular}


JRRD, Volume 49, Number 7, 2012

Table 4.

Logistic regression predicting likelihood of reporting axial pain.

\begin{tabular}{|c|c|c|c|c|c|c|c|}
\hline \multirow{2}{*}{ Variable } & \multirow{2}{*}{$B \pm \mathrm{SE}$} & \multirow{2}{*}{ Wald } & \multirow{2}{*}{$d f$} & \multirow{2}{*}{$p$-Value } & \multirow{2}{*}{ Odds Ratio } & \multicolumn{2}{|c|}{ 95\% CI for Odds Ratio } \\
\hline & & & & & & Lower & Upper \\
\hline Posttraumatic Stress & $0.02 \pm 0.01$ & 9.73 & 1 & $<0.001$ & 1.02 & 1.01 & 1.04 \\
\hline Disorientation Only vs No TBI & $0.14 \pm 0.28$ & 0.23 & 1 & 0.63 & 1.15 & 0.66 & 1.99 \\
\hline LOC vs No TBI & $0.48 \pm 0.31$ & 2.33 & 1 & 0.13 & 1.61 & 0.87 & 2.97 \\
\hline
\end{tabular}

Table 5.

Logistic regression predicting likelihood of reporting head/headache pain.

\begin{tabular}{|c|c|c|c|c|c|c|c|}
\hline \multirow{2}{*}{ Variable } & \multirow{2}{*}{$B \pm S E$} & \multirow{2}{*}{ Wald } & \multirow{2}{*}{$d f$} & \multirow{2}{*}{$p$-Value } & \multirow{2}{*}{ Odds Ratio } & \multicolumn{2}{|c|}{ 95\% CI for Odds Ratio } \\
\hline & & & & & & Lower & Upper \\
\hline Posttraumatic Stress & $0.02 \pm 0.01$ & 7.13 & 1 & 0.01 & 1.02 & 1.01 & 1.03 \\
\hline \multicolumn{8}{|l|}{ TBI Group } \\
\hline Disorientation Only vs No TBI & $0.59 \pm 0.28$ & 4.48 & 1 & 0.03 & 1.80 & 1.04 & 3.09 \\
\hline LOC vs No TBI & $1.06 \pm 0.31$ & 11.55 & 1 & $<0.001$ & 2.90 & 1.57 & 5.36 \\
\hline
\end{tabular}

\section{DISCUSSION}

The purpose of this study was to evaluate the pain experience in OIF/OEF veterans with and without a history of mTBI. The sample included veterans who screened positive on the TBI Clinical Reminder who participated in a secondary TBI evaluation. In this sample, reports of pain were high, with over 80 percent of the sample reporting pain and 20 to 30 percent reporting severe or extreme pain interference in daily life. These pain rates are higher than rates reported in other OIF/ OEF patient populations [2-3]. One explanation for this finding is that patients who screen positive on the TBI Clinical Reminder may represent a higher risk population because they responded positively to the question asking about injury during deployment (questions 1 and 2 on the TBI Clinical Reminder). These veterans were thus more likely to be exposed to physical and emotional injuries resulting in higher rates of pain than OIF/OEF veterans in general primary care. Another explanation may be that this study did not differentiate between transient and persistent pain, both of which could influence reports of pain and pain interference.

In terms of the pain experience, head/headache pain was the most commonly reported problem, with 71 percent of our sample endorsing head/headache pain. We did not find an association between mTBI and axial pain, but as expected, those with a history of mTBI and LOC were nearly three times as likely to report head/headache pain than those without a history of TBI. Analyses also found a trend for this group to report more areas of pain in comparison to the rest of the sample. These findings suggest that a history of mTBI with LOC may be a risk factor for more sites of pain and increased risk for head/headache pain.

Several important caveats to this relationship between pain and a history of mTBI can be made, though. First, PTSD symptom severity was found to have a strong relationship with both pain report and pain interference. In the sample as a whole, there was a clinically significant effect for PTSD symptomology on pain interference; every 10-point increase in the PCL resulted in a near doubling of reported pain interference. Second, a 10 -point increase in the PCL resulted in increased report of axial and head/headache pain.

Note that at its core, the finding of PTSD symptom severity having a strong relationship with pain and pain interference is correlational rather than causal, and a strong and defensible alternative model would be that the pain experience (with its avoidance and vigilance features, for example) potentiates some features of emotional distress that are concommittant with a PTSD diagnosis. Rather than implying causality, the above findings drive home the interwoven nature of the clinical phenomena and the need 
to assess and treat the conditions in tandem. For example, prior research has reported high rates of pain in the PTSD and general mental health populations [7,22]. Clinically, this implies that strongly integrating pain assessment into the mental health treatment settings may help better identify and address pain issues in mental health patients. Specific training in the assessment and treatment of pain with PTSD specialty providers may be helpful in addressing the comorbidity of these conditions. This is especially important because research has suggested that treating comorbid pain issues in the mental health population facilitates better mental health outcomes and recovery [18-19].

Another important finding is the relationship between a history of mTBI with LOC and head/headache pain. While Hoge's study found such a relationship in recently returning veterans [7], the fact that our sample, which was seen on average several years postdeployment, still demonstrated such a relationship suggests that head/headache pain may be an area of particular focus for assessment and treatment in this population. The fact that this finding was stronger in individuals with a history of LOC raises the possibility that a more severe, but still "mild," TBI may increase the risk of long-term head/ headache pain issues.

There are several limitations to the present study. First, we did not have a measure of subjective pain intensity. Thus, conclusions about the relationship between pain and pain interference and between pain and TBI symptoms are limited to report of the presence of pain rather than pain severity. Prior research has indicated that only about half of OIF/OEF veterans who report a pain problem report pain severity in the clinically significant range [2]. A second limitation is the lack of differentiation between transient pain and persistent pain. The polytrauma questionnaire asks only whether participants have had pain in the past 30 days. Pain complaints and ratings of pain interference therefore cannot be attributed to chronic pain as distinct from transient pain. Additionally, while the current study describes the experience of pain and the relationship between comorbidities, it does not attempt to answer causal questions such as what initiates and maintains pain.

\section{CONCLUSIONS}

The pain experience is one of the most complex facets of health to assess and treat. In returning combat veterans, the complexity is compounded by frequent comorbidities such as mTBI and PTSD. Future studies can build upon these findings by identifying which factors of treatment (such as treatment of emotional distress) can most effectively ameliorate pain and pain interference. Our results reinforce the growing consensus that a more comprehensive, biopsychosocial approach to the primary care of returning combat veterans may enhance the ability to detect, characterize, and treat comorbid physical and psychological conditions as seen in this population [27].

\section{ACKNOWLEDGMENTS}

\section{Author Contributions:}

Study concept and design: J. Romesser, J. Booth, N. Pastorek, J. Benge.

Acquisition of data: J. Romesser, N. Pastorek.

Analysis and interpretation of data: J. Romesser, J. Booth, N. Pastorek, J. Benge.

Drafting of manuscript: J. Romesser, J. Booth, N. Pastorek, J. Benge. Critical revision of manuscript for important intellectual content:

J. Romesser, J. Booth, N. Pastorek, J. Benge, D. Helmer.

Statistical analysis: J. Booth, N. Pastorek, J. Benge.

Financial Disclosures: The authors have declared that no competing interests exist.

Funding/Support: This material was unfunded at the time of manuscript preparation.

Institutional Review: The study was reviewed and approved by the local internal review boards.

\section{REFERENCES}

1. Kalra R, Clark ME, Scholten J, Murphy JL, Clements KL. Managing pain among returning service members. Fed Pract. 2008;25(10):36-45.

2. Gironda RJ, Clark ME, Massengale JP, Walker RL. Pain among veterans of Operations Enduring Freedom and Iraqi Freedom. Pain Med. 2006;7(4):339-43. [PMID:16898945] http://dx.doi.org/10.1111/j.1526-4637.2006.00146.x

3. Helmer DA, Chandler HK, Quigley KS, Blatt M, Teichman $\mathrm{R}$, Lange G. Chronic widespread pain, mental health, and physical role function in OEF/OIF veterans. Pain Med. 2009;10(7):1174-82. [PMID:19818029]

4. Lew HL, Otis JD, Tun C, Kerns RD, Clark ME, Cifu DX. Prevalence of chronic pain, posttraumatic stress disorder, and persistent postconcussive symptoms in OIF/OEF veterans: polytrauma clinical triad. J Rehabil Res Dev. 2009; 46(6):697-702. [PMID:20104399] http://dx.doi.org/10.1682/JRRD.2009.01.0006 
5. Belmont PJ Jr, Thomas D, Goodman GP, Schoenfeld AJ, Zacchilli M, Burks R, Owens BD. Combat musculoskeletal wounds in a US Army Brigade Combat Team during Operation Iraqi Freedom. J Trauma. 2011;71(1):E1-7.

[PMID: 21045748]

http://dx.doi.org/10.1097/TA.0b013e3181edebed

6. Hauret KG, Jones BH, Bullock SH, Canham-Chervak M, Canada S. Musculoskeletal injuries description of an under-recognized injury problem among military personnel. Am J Prev Med. 2010;38(1 Suppl):S61-70. [PMID:20117601] http://dx.doi.org/10.1016/j.amepre.2009.10.021

7. Hoge CW, McGurk D, Thomas JL, Cox AL, Engel CC, Castro CA. Mild traumatic brain injury in U.S. soldiers returning from Iraq. N Engl J Med. 2008;358(5):453-63. [PMID:18234750] http://dx.doi.org/10.1056/NEJMoa072972

8. Schneiderman AI, Braver ER, Kang HK. Understanding sequelae of injury mechanisms and mild traumatic brain injury incurred during the conflicts in Iraq and Afghanistan: persistent postconcussive symptoms and posttraumatic stress disorder. Am J Epidemiol. 2008;167(12): 1446-52. [PMID:18424429] http://dx.doi.org/10.1093/aje/kwn068

9. Mittenberg W, Tremont G, Zielinski RE, Fichera S, Rayls KR. Cognitive-behavioral prevention of postconcussion syndrome. Arch Clin Neuropsychol. 1996;11(2):139-45. [PMID:14588914]

10. Belanger HG, Curtiss G, Demery JA, Lebowitz BK, Vanderploeg RD. Factors moderating neuropsychological outcomes following mild traumatic brain injury: a metaanalysis. J Int Neuropsychol Soc. 2005;11(3):215-27. [PMID:15892898] http://dx.doi.org/10.1017/S1355617705050277

11. Schretlen DJ, Shapiro AM. A quantitative review of the effects of traumatic brain injury on cognitive functioning. Int Rev Psychiatry. 2003;15(4):341-49. [PMID:15276955] http://dx.doi.org/10.1080/09540260310001606728

12. Ivins BJ, Kane R, Schwab KA. Performance on the Automated Neuropsychological Assessment Metrics in a nonclinical sample of soldiers screened for mild TBI after returning from Iraq and Afghanistan: a descriptive analysis. J Head Trauma Rehabil. 2009;24(1):24-31.

[PMID:19158593]

http://dx.doi.org/10.1097/HTR.0b013e3181957042

13. McCrea M. Mild traumatic brain injury and postconcussion syndrome: The new evidence base for diagnosis and treatment. New York (NY): Oxford University Press; 2008.

14. Uomoto JM, Esselman PC. Traumatic brain injury and chronic pain: differential types and rates by head injury severity. Arch Phys Med Rehabil. 1993;74(1):61-64. [PMID:8420522]
15. Lahz S, Bryant RA. Incidence of chronic pain following traumatic brain injury. Arch Phys Med Rehabil. 1996; 77(9):889-91. [PMID:8822679] http://dx.doi.org/10.1016/S0003-9993(96)90275-0

16. Nampiaparampil DE. Prevalence of chronic pain after traumatic brain injury: a systematic review. JAMA. 2008; 300(6):711-19. [PMID:18698069] http://dx.doi.org/10.1001/jama.300.6.711

17. Otis JD, Keane TM, Kerns RD, Monson C, Scioli E. The development of an integrated treatment for veterans with comorbid chronic pain and posttraumatic stress disorder. Pain Med. 2009;10(7):1300-1311. [PMID:19818040] http://dx.doi.org/10.1111/j.1526-4637.2009.00715.x

18. Sherbourne CD, Asch SM, Shugarman LR, Goebel JR, Lanto AB, Rubenstein LV, Wen L, Zubkoff L, Lorenz KA. Early identification of co-occurring pain, depression and anxiety. J Gen Intern Med. 2009;24(5):620-25. [PMID:19308333] http://dx.doi.org/10.1007/s11606-009-0956-2

19. Tunks ER, Crook J, Weir R. Epidemiology of chronic pain with psychological comorbidity: prevalence, risk, course, and prognosis. Can J Psychiatry. 2008;53(4):224-34. [PMID:18478825]

20. Ohayon MM. Specific characteristics of the pain/depression association in the general population. J Clin Psychiatry. 2004;65(Suppl 12):5-9. [PMID:15315471]

21. Von Korff M, Ormel J, Keefe FJ, Dworkin SF. Grading the severity of chronic pain. Pain. 1992;50(2):133-49.

[PMID:1408309] http://dx.doi.org/10.1016/0304-3959(92)90154-4

22. Shipherd JC, Keyes M, Jovanovic T, Ready DJ, Baltzell D, Worley V, Gordon-Brown V, Hayslett C, Duncan E. Veterans seeking treatment for posttraumatic stress disorder: what about comorbid chronic pain? J Rehabil Res Dev. 2007; 44(2):153-66. [PMID:17551870] http://dx.doi.org/10.1682/JRRD.2006.06.0065

23. Von Korff M, Simon G. The relationship between pain and depression. Br J Psychiatry Suppl. 1996;168(30):101-8. [PMID:8864155]

24. Belanger HG, Uomoto JM, Vanderploeg RD. The Veterans Health Administration's (VHA's) Polytrauma System of Care for mild traumatic brain injury: costs, benefits, and controversies. J Head Trauma Rehabil. 2009;24(1):4-13. [PMID:19158591] http://dx.doi.org/10.1097/HTR.0b013e3181957032

25. DVBIC Working Group. Clinical practice guide line and recommendations: Acute management of mild traumatic brain injury in military operational settings. Washington (DC): Defense and Veterans Brain Injury Center; 2006.

26. American Psychiatric Association. Diagnostic and statistical manual of mental disorders: DSM-IV. Washington (DC): American Psychiatric Association; 2000. 
27. Gironda RJ, Clark ME, Ruff RL, Chait S, Craine M, Walker $\mathrm{R}$, Scholten J. Traumatic brain injury, polytrauma, and pain: challenges and treatment strategies for the polytrauma rehabilitation. Rehabil Psychol. 2009;54(3):247-58.

[PMID:19702423]

http://dx.doi.org/10.1037/a0016906

Submitted for publication December 16, 2010. Accepted in revised form June 17, 2011.
This article and any supplementary material should be cited as follows:

Romesser J, Booth J, Benge J, Pastorek N, Helmer D. Mild traumatic brain injury and pain in Operation Iraqi Freedom/Operation Enduring freedom veterans. J Rehabil Res Dev. 2012;49(7):1127-36.

http://dx.doi.org/10.1682/JRRD.2010.12.0238

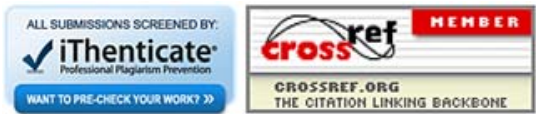


